\title{
Project Guesstimation System
}

\author{
Aishwarya Ingle ${ }^{1}$, Akanksha Nandgaonkar ${ }^{2}$, Bhawana Prakash ${ }^{3}$, Rucha Bobade $^{4}$, Yogesh Narekar \\ U.G. Student, Information Technology, RGCER, Nagpur, Maharashtra, India ${ }^{1,2,3,4}$ \\ Assistant Professor, Information Technology, RGCER, Nagpur, Maharashtra, India ${ }^{5}$
}

\begin{abstract}
Academic Project management is a major issue which is faced by many educational institutes. The main reason for this is there is no automated system followed in any institute. College management/staff gathers all the project reports and project sources from students and store them physically in some locations probably libraries. To overcome this practical problem and also to make the process easy we developed a secured intranet application which is useful for each. This project realizes several functionalities such as: reducing redundant tasks; giving productive workflow with efficiency; and, providing centralized and consolidated feedback from the approver, reduced risk of errors, increased functional security, message encryption, and improved tracking progress status. This will reduce the physical efforts of students meeting the guide and also reduce the time frame period of completing this part of project work. Students can also update their project status weekly and provide in for regarding the progress, which will be monitored by all relevant professors and head of departments. It will be useful for all students related to Engineering, MSc, M.Tech, final year students of any grad etc.
\end{abstract}

Keyword: Project Management, Project Evaluation, Project Approval and project Updating

\section{INTRODUCTION}

This paper will allow the students to login and upload/enter all his/her personal details and then after filling the details he/she will enter/upload the details regarding the project such as selection of topic, formation of group ,updating names of group members etc. Every updated information will be displayed on this application to students.After this the approval will done by the guide or head of department on whether the students should proceed and start working on projects.

According to the date displayed on this application every group shall presents and upload their abstract and synopsis and also it should mention what work is done by which student. Thus, this process will be carried on which will help all the students as well as faculty members to access this application easily as it is digital.

In this research paper, we will focus mainly on automating the process of project submission. In the sense project topics will be submitted online along with doc and approval will be provided online by the head of the department along with suggestions if any.

This will reduce the physical efforts of students meeting the guide and also reduce the time frame period of completing this part of project work. Students can also update their project status weekly and provide in for regarding the progress, which will be monitored by all relevant professors and head of departments. It will be useful for all students related to Engineering, MSc, M.Tech, final year students of any graduation etc.

\section{MODULES AND FUNCTIONALITIES}

In this project we have 5 major roles:

$\begin{array}{ll}\text { 1. } & \text { Admin } \\ \text { 2. } & \text { Student } \\ \text { 3. } & \text { HOD } \\ \text { 4. } & \text { Project In charge } \\ \text { 5. } & \text { Guide }\end{array}$

\section{Admin}

In this project Admin should have the all authority, i.e., he/she can add the role, stream, Academic year and Employee his Credential and Department. Admin have the all authority in this as project given below :- 
Vol. 8, Issue 2, February 2019

\author{
- $\quad$ Add Role \\ - $\quad$ Add Stream \\ - $\quad$ Add Academic Year \\ - $\quad$ Add Document Category \\ - $\quad$ Add Sem-Year \\ - $\quad$ Add Department \\ - $\quad$ Add Sub Department \\ - $\quad$ Employee Credential \\ - $\quad$ Add Employee \\ - Upload Student Details
}

\title{
2.Student:
}

Student can login and post all his project details and he/she can view his/her project details online. The following task can be done by students :-

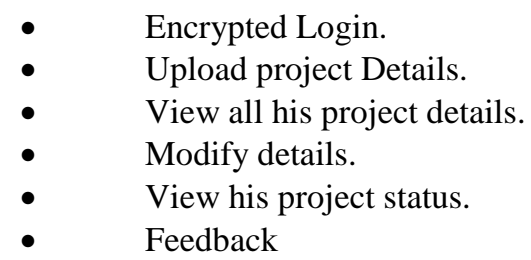

\section{HOD:}

HOD plays vital roles in our application projects the information posted by students are first viewed by HOD if HOD approves then only next level people can view the project details:

- $\quad$ Encrypted Login* [Even In database also the values will not be exposed].

- $\quad$ View Project details.

- $\quad$ Approve project details

- $\quad$ Auto project update (if HOD logs into site if there are any unread project details those things are highlighted in the main home page of user).

- $\quad$ Project Feedback (HOD can give his feedback on projects which can be views by that project related student).

- $\quad$ Downloading/Delete Project/Feedback.

\section{Project In charge:}

After project is accepted by HOD, the project in charge can view the project details given as follows :-

- View Project details.

- $\quad$ Modifications in project (feedback).

- $\quad$ Delete projects / Downloading documents.

- $\quad$ Approve project

\section{Guide:}

After project in charge approve the project then internal guide can view the project details. They can have the command on the projects which are allocated to them.

At the final, the students will have to prepare the necessary Documents like Project Final Document (contains Introduction, Modules, User roles, SDLC methodology, etc.), UML Diagrams, PowerPoint Presentation (PPT) of the Project flow for Demo and also takes the Database (as backup file to restore), Source Code and all the content in a Compact Disk (CD) and submits to the HOD along with printed hard copy. The HOD will review all these documents and finishes the Project Review and enters the Marks into the College records. 


\section{LITERATURE SURVEY}

Projects are widely recognized now a days by organizations. They are part of the activities of both education .However, despite garnering experience and improving on available methods, a significant number of projects (including educational ones) still fail.

\section{ELEMENTS OF AN APPROVAL PROCESS}

While each approval process will differ based on its purpose or the organization's specific requirements, there are some general tasks that you will likely include when designing your own. These include:

- Submission: An approval process usually begins with someone submitting something (a document, invoice, purchase order, etc.).

- Assign Approvers: The approval process hinges on someone else (not the submitter) approving the work, so you'll need to identify the person or people who have the final say.

- Set Permission Levels: Define the level of authority each user should have.

- Set Due Dates: As with any project, it's important to set deadlines to keep your workflows moving and prevent work backlogs.

- Automatic Alerts and Notifications: A program that automatically sends alerts and notifications about the status of a submission can help expedite workflow.

- Record/Log: Having a record of every step in the approval process.

This is one of its greatest as well as benefits for increasing transparency and ensuring consistency.

- Lock Record: This will make the record uneditable, so that no user can change the log of actions.

- Edit Record: In some cases, you might want the record to be kept editable - for instance, if you made a mistake or need to keep certain information private from other parties.

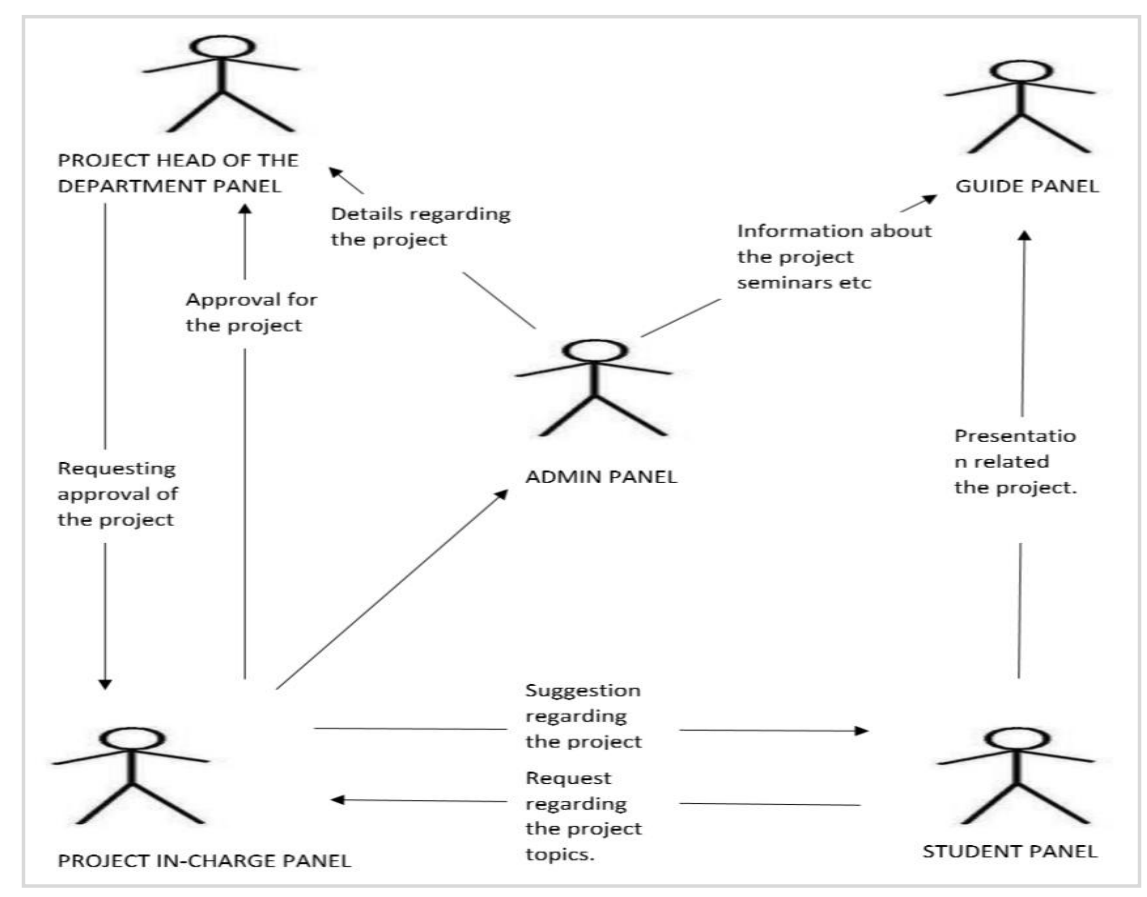

Fig: Implementation Of Project

\section{CONCLUSION}

In this research paper, using this web application the above entire flow can be automated so that the student need not submit any hard copy of the project as well ,the college need not maintain all the collected hard copy for records. In general the project and title will be selected from various sources and send it to the project guide along with the bird's eye view of the project in document called project abstract. The guide will accept the project and allow the student to proceed and work on the project. 


\section{ACKNOWLEDGMENT}

We take an opportunity to acknowledge and extend our gratitude to our Project Guide Prof. Yogesh Narekar Professor of Information Technology, RGCER, Nagpur. He has helped us in many ways. His enthusiastic engagements in our project work and his never-ending stream of ideas have been absolutely essential for the results, presented here. We are very grateful that she has spent so much time with us discussing different problems ranging from philosophical issues down to minute technical details. We would also like to express our sincere thanks to Prof. Alok Chauhan Asst. Professor of IT, Rajiv Gandhi College of Engineering and Research, Nagpur for his Guidance and kind support. We express our deepest sense of gratitude to Dr. Manali Kshirsagar, Principal, RGCER, Nagpur.

We also extend our thanks to all the faculty members of the department for providing their cooperation. Finally, we would like to thanks to everybody who has directly or indirectly contributed to our project work.

\section{REFERENCES}

[1]. [https://googleweblight.com/i?u=https://www.geeksforgeeks.org/computer-science-projects/\&hl=en-IN

[2]. https://googleweblight.com/i?u=https://www.geeksforgeeks.org/b-tech-project-idea-remote-lab-assistance/\&hl=en-IN\&tg=310\&pt=62

[3]. http://www.welightedu.in/2014/12/college-project-approval-system-java.html

[4]. http://1000projects.org/e-approval-system-java-project.html

[5]. https://www.tutorialspoint.com/software_engineering/software_project_management.htm

[6]. https://try.wrike.com/all-in-one-collaboration-project-managementsoftware/?ga_campaign=(roi)+project+management++apac+in\&ga_adgroup=project+management+tool\&ga_keyword=project\%20management\%20tools\&gclid=CjwKCAiA_P3jBRAqEiwAZyW WaCEt0vSQdlsu6rg6cUjO477_pmPkSgUh9BDyzp6xJDOI0pFspAPyUBoCv3oQAvD_BwE 